\title{
Speech Pathologists' Perceptions of the Impact of Student Supervision
}

\author{
*Elizabeth Bourne ${ }^{a}$, Lindy McAllister ${ }^{a}$, Belinda Kenny $^{b}, \&$ Kate Short ${ }^{c}$ \\ a: University of Sydney, Australia; b: Western Sydney University, Australia; c: Liverpool Hospital \\ and Ingham Institute, Australia
}

\begin{abstract}
Qualitative studies have described clinician perspectives on student placements. These studies highlight likely contributors to placement shortages, but little is documented in speech pathology (SP). This article describes SP clinician perceptions of student impact/s on their clinical and other work tasks, stress levels and time management, and explores factors that may contribute to these perceptions of their experience. Interpretive description was selected to analyse public health sector SP clinician online survey responses. Open-ended questions explored clinician perceptions of student impact on specified components of their work as well as any other aspects clinicians identified. Thirty-four SP clinicians with varying caseloads and experience levels responded. Clinicians perceived that students can positively or negatively impact their clinical and non-clinical activities. Many also identified negative impacts on their stress levels. Some commented on differing impacts for patients and other colleagues. Collective themes of Clinician, Supervision Practices, Workplace, and Student are presented in a model of potential influences on the experience of student impact. SP clinicians perceived that experience of student impact is varied and complex. Influences are likely to be multi-factorial and further research is needed in a range of contexts to guide clinicians, managers and universities in supporting SP student clinical placements.
\end{abstract}

Keywords: clinical education; perception; placement impact; speech pathology; student placement

\section{Introduction}

Increased student enrolments and greater workforce pressures are documented in speech pathology (SP) (Briffa \& Porter, 2013), as is the shortage of student clinical placements internationally (Mancinelli \& Amster, 2015; Read, 2014). Central to student placements is the clinical supervisor, who utilises many skills and practices to facilitate student learning (Francis et al., 2016). In Australia, SP student supervisors are predominantly qualified speech pathologists employed as clinicians in a variety of workplace settings. These SP clinicians mostly volunteer for the additional responsibility of student supervision on an ad hoc basis. Hence, they need to manage the "role strain" (Barton et al., 2013, p. 317) associated with fulfilling supervisory responsibilities while maintaining routine workplace roles. Given their pivotal role in

*Corresponding Author: Elizabeth Bourne, Work Integrated Learning, Sydney School of Health Sciences, University of Sydney, NSW 2006, Australia.

Email: elizabeth.bourne@sydney.edu.au

Journal URL: https://publications.coventry.ac.uk/index.php/pblh

Bourne, E., McAllister, L., Kenny, B., \& Short, K. (2020). Speech pathologists' perceptions of the impact of student supervision. International Journal of Practice-based Learning in Health and Social Care, 8(2), 1-15. DOI 10.18552/ijpblhsc.v8i2.549

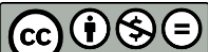

(C) BY ND (C) 2020 Elizabeth Bourne, Lindy McAllister, Belinda Kenny, \& Kate Short. This Open Access article is distributed under the terms of the Creative Commons Attribution Attribution-Non-Commercial No Derivatives 4.0 International License (https://creativecommons.org/licenses/by-nc-nd/4.0/ ), which permits unrestricted non-commercial use, distribution, and reproduction in any medium, provided the original work is properly cited and is unaltered. 
facilitating student competency development within the workplace, understanding the nature of student impact on SP clinicians is necessary to implement mutually beneficial placements within challenging workplaces.

There are limited studies measuring or describing SP clinician perspectives on student impact within clinical settings. Higgs \& McAllister (2007, pp. 194, 196) presented six dimensions in the clinician experience of student supervision, and portrayed the role complexity using metaphors such as a 'juggler'. In exploring risks with students, Morris (2001) found that, while the dominant concern was for patients, clinicians considered most adverse patient impacts (if they occurred) had only temporary or minor consequences. Studies of specific models have reported varied student impacts on caseload and time management (Cocks et al., 2014; Dawes \& Lambert, 2010; Thomasz \& Young, 2016). Each study also showed clinicians vary in their views on placements (e.g. from seeing opportunities for extra services, to perceiving increased stress). In contrast, recent quantitative studies found no significant difference in clinical time or patient activity when SP students were present (Bhagwat et al., 2018; Bourne, McAllister et al., 2019). However, each study found some reductions in non-clinical time during placements. More comprehensive understanding of the wide-ranging beliefs within SP regarding student impact is central to maintaining sufficient quality placements.

Clinician stress or sense of burden has been repeatedly highlighted in allied health placements (e.g. Ingwersen et al., 2017; Öhman et al., 2005). These emotional impacts have been linked to negative experiences such as delaying usual tasks (Sevenhuysen \& Haines, 2011) or failing a student (Foo et al., 2017). However, Davies et al. (2011) reported increased stress even when student(s) were progressing well, suggesting clinicians had a sense of diminished independence. Furthermore, Hall et al. (2016) attributed stress (in part) to a fear of student judgement about the clinician's clinical competence and the clinician's perception that they were ill-equipped to supervise students. Overall, clinician stress was the most influential contributor in physiotherapists' decisions to supervise students ( Hall et al., 2016). Clearly, identifying any factors leading to perceptions of stress in SP placements should be prioritised.

This article aims to:

(1) Describe public health sector SP clinician perceptions of student impact on their clinical and non-clinical work tasks, time management and stress levels;

(2) Identify factors that contribute to SP clinician perceptions of student impact during placements.

\section{Methods}

\section{Research approach}

Interpretive description is a contemporary qualitative method affiliated with "interpretive naturalistic orientation" (Thorne et al., 2004, p. 3). Interpretive description is suited to understanding clinical workplace challenges (Hunt, 2009), and has been used to investigate placements in health professions (e.g. Ryan \& McAllister, 2018). Interpretive description (Thorne, 2016) not only facilitated examination of a range of views regarding student impact but allowed re-conceptualisation of patterns within and across divergent views to aid application of results to SP workplaces.

\section{Participants and study context}

Ethics applications for a broader mixed-methods study were approved by Human Research Ethics Committees from the University of Sydney and six health districts in one Australian state. These districts provide government-funded health services to Australian residents living within their geographical boundaries. Clinicians may provide one or more service types including inpatient or outpatient hospital care, and community- or home-based services in order to prevent illness or to maintain or improve quality of life. A diverse sample was desired to facilitate broad description of perceptions and influences on student impact. Speech pathologists within approved districts received project information, including a participant information sheet and consent form, via email from a senior clinician to avoid the risk of coercion. Because of this process, the number of clinicians contacted is unknown. Interested clinicians supervising any SP students in 2015 contacted the first author to provide written consent or to raise any queries. 


\section{Instrument and procedure}

A survey was developed to profile clinician roles (multiple choice) and establish their supervision practices and beliefs regarding student impact (free text responses). This approach was selected over more time-intensive methods for participants (e.g. interviews) to facilitate participation in all components of this exploratory study. Published themes within allied health qualitative literature and author experience working with SP placements guided the areas of exploration. This article reports participant responses to five open-ended questions: 'What effects do you believe students have on your 1) clinical work, 2) other work tasks, 3) time management, 4) stress level', and 5) 'Please describe any other effects not covered by the above categories'.

Clinicians completed this survey online via REDCap® (Research Electronic Data Capture https://www.project-redcap.org/), a secure web-based application (Harris et al., 2009). Participants were emailed the survey link prior to placement commencement and reminded if the survey was not completed by the middle of the first placement week.

\section{Situating the authors}

Three authors (EB, BK and KS) have worked within the public health sector agency being studied, including supervising students. Three authors (EB, LM, BK) teach and research allied health placements subjects. Furthermore, two authors (LM and BK) are highly skilled in qualitative methods and guided data collection and analysis.

\section{Data management and analysis}

Data from the REDCap application were downloaded into a Microsoft $®$ Excel file and stored on a secure file server throughout analysis. Descriptive statistics were used to examine demographic variables. Given the limited research in SP, inductive analysis methods were selected to examine open-ended survey responses. The interpretive description method involved initial coding to describe clinician perceptions using content analysis (Hsieh \& Shannon, 2005), then rigorous reflection and critical examination to move beyond description into clinical application (Thorne, 2016). This interpretive second stage was an iterative process which involved regularly returning to the original data, as well as integrating literature and authors' understanding of the context.

In the first stage, two or more researchers (EB plus LM and/or SN) independently coded responses to each question and collapsed codes into categories to describe clinician perceptions. All sets of codes and categories were then collated by EB into a central Excel file and, through further discussion and data review with all researchers, consensus was achieved that codes and categories represented all key ideas. EB then re-coded all material according to the agreed categories and codes.

Before interpretive analysis of the codes and categories occurred, some authors completed a systematic review of quantitative studies in allied health student placements (Bourne, Short et al., 2019) and published quantitative data regarding SP placements (Bourne, McAllister et al., 2019). In returning to the categories and codes with these new insights, further questions arose such as 'Are the divergent views due to the same factors suggested in quantitative studies (e.g. caseload)?' With these questions in mind, in accordance with interpretive description processes (Thorne, 2016), EB completed repeated readings of the original data and compared responses within categories for both similarities and differences; for example, perceived negative versus positive impacts on clinical work. Interpretations were also informed by qualitative literature reporting clinician perceptions of allied health placements, which prompted research team questions such as 'Do responses vary according to factors reported in other studies (e.g. student characteristics)?' This iterative process identified themes of influence within and across categories which were then mapped for each question. These themes were collated and compared, leading to the identification of major themes across all questions. Themes were reviewed by all authors until consensus was reached.

\section{Rigour}

Several strategies ensured "trustworthiness" of results in accordance with Lincoln \& Guba (1985, p. 290). Firstly, a detailed audit trail of coding methods was kept throughout analysis. Secondly, multiple researchers were used to code and categorise raw data independently. Following this, categories and 
codes were revised by the wider group and evidenced with reference to original responses. Similarly, the outcome themes and conceptual representation were reviewed and revised by all authors, with discussion referencing original data as required to verify interpretations.

\section{Findings}

Thirty-seven SP clinicians responded to the survey, although only thirty-four answered the questions being reported in this paper. Two of the three clinicians with missing responses wrote 'N/A' (not applicable), with one explaining they had 'never supervised students' (C27) and the third clinician left the questions blank. The remaining thirty-four clinicians commented on each of the four topic areas (questions 1-4 of the survey), with the exception of three clinicians who each did not respond to one topic question. Seven clinicians made additional comments (question 5 of the survey). Clinicians had varying clinical and supervision experience (see Table 1). Reported years of clinical experience were fairly evenly distributed across the provided categories, but two to five years of supervisory experience was most commonly reported (19/34).

Table 1: Experience in the roles of clinician and supervisor

\begin{tabular}{|l|c|}
\hline Years & Number $(\boldsymbol{n}=\mathbf{3 4})$ \\
\hline As a Clinician & 8 \\
$0-3$ & 9 \\
$4-6$ & 8 \\
$7-10$ & 9 \\
$11+$ & \\
\hline As a Student Supervisor & 4 \\
$0-1$ & 18 \\
$2-5$ & 8 \\
$6-9$ & 4 \\
$10+$ & \\
\hline
\end{tabular}

In relation to their current responsibilities, the most common role classification selected by clinicians was the base grade (19/34). Six clinicians reported having senior clinical or managerial roles (level four), including as head of a small department. The highest classification selected identified participants as senior clinicians including roles as head of small department (6/34). Most participants reported working with an adult caseload (29/34) and the majority with hospital inpatients (20/34).

Content analysis identified several categories per question (see Table 2). Each category consisted of between one and five codes. A complete list of categories, codes and exemplar quotes is available in the Appendix.

Table 2: Categories arising from content analysis of responses to each survey question

\begin{tabular}{|c|c|}
\hline Topic of impact & Categories \\
\hline $\begin{array}{l}\text { What effect do you believe } \\
\text { students have on your: }\end{array}$ & \\
\hline 1. Clinical work? & impact on patient activity, impact on time, impact on clinician \\
\hline 2. Other work tasks? & impact of student, responses to impact, impact on clinician \\
\hline 3. Time management? & positive impact, neutral/ limited impact, negative impact, responses to impact \\
\hline 4. Stress level? & increased stress, no impact on stress level, responses to manage stress \\
\hline $\begin{array}{l}\text { Please describe any other } \\
\text { effects not covered by the } \\
\text { above categories }\end{array}$ & depends on student, impact on clinician, impacts on other staff and department. \\
\hline
\end{tabular}

\section{Key perceptions of student impact}

Clinician comments indicated students may favourably or unfavourably impact a clinician's patient activity levels and time-use (clinical and other duties). Many clinicians also perceived that supervising students impacted the clinician as an individual, both negatively (e.g. altering stress levels) or more 
positively (e.g. enhancing their clinical reasoning). The wider impact of students on patients or colleagues (in SP or other professions) was noted by some clinicians.

\section{Factors contributing to perceptions of student impact}

Four major integrative themes reflected individual perceptions of student impact: Influence of Clinician; Influence of Supervision practices; Influence from Workplace; and Influence of Student (see Figure 1).

Figure 1: Model of influences on SP student impact

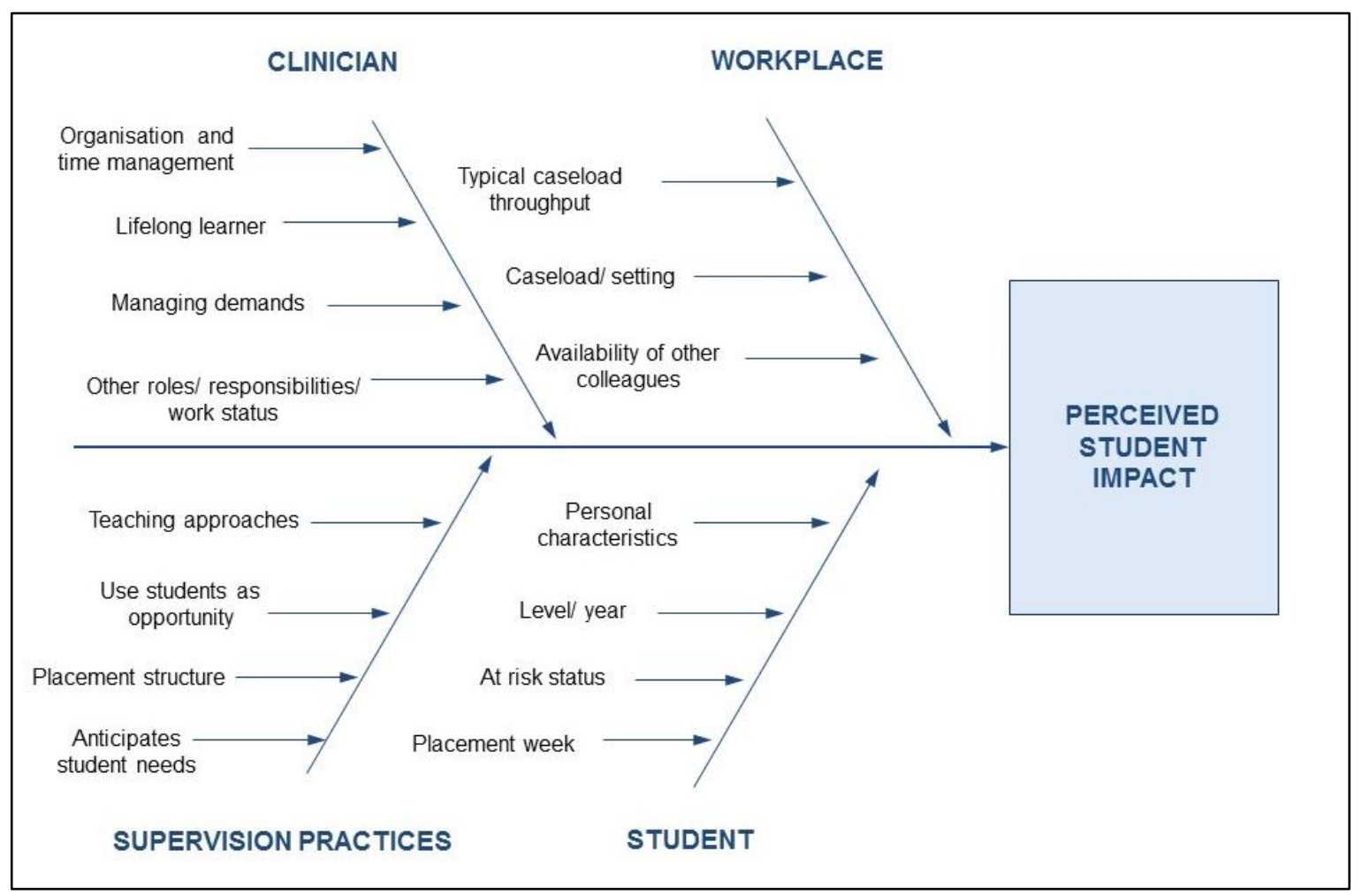

Table 3 provides an example of links from codes and categories (agreed during initial content analysis) to the influences identified during the second stage of analysis. The four themes of influence on clinician perceptions of student impact will be further illustrated using exemplar quotes.

\section{Influence of clinician}

Nearly all clinicians mentioned internal traits or structural influences on their experience of student impact. Most frequently, clinicians identified their responsibility in time management during placements and some reported strategies they used: for example, deferring less urgent tasks. Organisation and timemanagement skills were identified by most clinicians typically supervising multiple students, but only by a quarter of clinicians supervising single students. Half of all clinicians described increased attention and diligence with time management during placements, and some identified the need to improve their skills:

I do feel that in the past that having students has reduced my time to complete other work tasks such as admin-related tasks, however this is something that I can also continue to work on to try and create better routines and time management systems in place. (C9)

Multiple comments suggested that flexibility in managing time and tasks facilitated a more positive experience. However, clinicians who allowed students to push time boundaries described student impact more negatively:

Generally I find myself leaving work late every day when I have students as I don't have $100 \%$ control over my time management. As much as I try to encourage/enforce, progress notes are not available to sign off until after my work day ends. Naturally students have lots of questions and this can be very hard to fit into the limited time we have. (C23) 
Table 3: Example linking inductive codes and categories to possible influencing factors

\begin{tabular}{|c|c|c|c|}
\hline Category & Code & Example quote & Possible influence \\
\hline \multirow{4}{*}{$\begin{array}{l}\text { Increased } \\
\text { stress level }\end{array}$} & \multirow[b]{2}{*}{ Depends on student } & $\begin{array}{l}\text { Depending on the level and capabilities of the } \\
\text { student. It can have varying degrees of impact on } \\
\text { stress levels, slight to significant (C6) }\end{array}$ & $\begin{array}{l}\text { Influence of student: } \\
\text { Student level/ year } \\
\text { At risk status }\end{array}$ \\
\hline & & $\begin{array}{l}\text { Depends on the student's competence...the process } \\
\text { of dealing with a struggling student requires lots of } \\
\text { support from my team to assist with coverage of } \\
\text { patient load and support with the student's teaching. } \\
\text { (C28) }\end{array}$ & $\begin{array}{l}\text { Influence of student: } \\
\text { At risk status } \\
\text { Influence of workplace: } \\
\text { Availability of other } \\
\text { colleagues }\end{array}$ \\
\hline & $\begin{array}{l}\text { Depends on } \\
\text { supervision experience } \\
\& \text { model }\end{array}$ & $\begin{array}{l}\text { For me as a more junior clinician with not much CE } \\
\text { experience, I probably feel a bit more stressed about } \\
\text { having } 2 \text { or } 3 \text { students at a time because it's not } \\
\text { what I'm used to and I probably don't feel } \\
\text { completely comfortable yet with my explanations } \\
\text { and teaching about things! (C1) }\end{array}$ & $\begin{array}{l}\text { Influence of supervision } \\
\text { practices: } \\
\text { Teaching approaches }\end{array}$ \\
\hline & $\begin{array}{l}\text { Need to meet own } \\
\text { clinical \& non- clinical } \\
\text { commitments }\end{array}$ & $\begin{array}{l}\text { Sometimes stress increases towards the end of the } \\
\text { day when I realise I have not managed to get } \\
\text { through the patients/clinical duties as I had needed } \\
\text { to - I also work part time so have to allocate time } \\
\text { for clinical handover etc. at the end of the day (C17) }\end{array}$ & $\begin{array}{l}\text { Influence of clinician: } \\
\text { Other roles/ } \\
\text { responsibilities/ Work } \\
\text { status }\end{array}$ \\
\hline
\end{tabular}

A few clinicians recalled seeking assistance within their workplace or from the university. Clinicians suggested this mitigated student impact on their stress or clinical work:

...If at anytime in the past I have felt overwhelmed about this I have gone to my manager and discussed it with her or if I have had to have a difficulty [sic] conversation with a student I have not only liaised with my manager but discussed it with the university. (C9)

Student impact also seemed influenced by clinician attitude and response to new learning. Many responses suggested clinicians were lifelong learners, and included positive student impacts on their knowledge and reasoning skills:

I believe, on the whole, they allow you to look at numerous perspectives and alternative treatment approaches. Engagement in discussion re clinical cases can be both stimulating and rewarding. (C29)

Clinicians with some role mixes, for example, those with managerial duties such as staff supervision or other factors such as working part-time, perceived that they were especially impacted by students.

\section{Influence of supervision practices}

Clinician understanding of student learning and approaches to placement management also appeared to have a strong influence on student impact. More than two-thirds of clinicians commented that facilitating students' learning required additional time. While linked to clinician time-management abilities, viewingtime demands in the context of student learning needs appeared to assert a separate influence on placement impact. Some clinicians provided insight into what the extra time demands entailed, such as describing supervisory tasks they managed:

...duties in providing feedback / amending paperwork / reports, working towards goals, organising learning opportunities for them etc. (C33)

Responses such as implementing different teaching strategies (e.g. peer learning) was often portrayed as a more efficient experience:

Increased time management and planning is required however is able to be managed. A student pair can be reading notes and planning the session whilst I see a patient etc. (C20) 
Other reported practices included giving students responsibility for their own time- and task-management. Clinicians suggested this reduced expectations of constant contact with students, and enabled efficiencies such as clinicians completing other tasks when not directly needed by the student(s):

It's important to set up roles from the beginning - so that the students can access assistance from you when needed, but also maintain independence and responsibility for their own time. (C5)

Some clinicians spoke positively about utilising students to add value either in project work or in additional clinical services:

...students I've had in the past have participated in [quality improvement] projects I've been working on and have helped collect data and write up reports. (C1)

Organisationally, a few clinicians pointed to placement timetabling and identified the negative impact of supervising students continually:

I had a student for 3 weeks ( 5 days a week) and it was too much. She was a lovely girl but I found I needed at least a day a week where I could catch up on admin or do something without her there. (C35)

\section{Influence from workplace}

Workplace influences included caseload factors and cultural aspects such as departmental support. More than half the clinicians surveyed associated perceptions of student impact with their work context.

Caseload features were predominantly noted by clinicians describing impacts on their clinical work and time management. Clinicians working with specialist outpatient settings or inpatient settings with caseload throughput targets most commonly reported negative impacts. Many identified impact on their stress levels:

To be completely honest, I find student supervision in this busy acute setting very stressful at times. I have a very busy caseload, where I am required to see up around 8-10 pts per day. If students are seeing the patients under my supervision, we are generally only able to get through about 4 patients per day. Unfortunately there is a limited amount that students can do independently with an acute predominantly dysphagia caseload. (C33)

However, a few clinicians in similar contexts described a culture where other clinicians assisted their workload management which alleviated some stress:

...fortunately in the model we have, the other clinicians are there for support and to assist you with managing this [stress]. It's a great model because you feel supported and able to take time out if things are busy. (C34)

In contrast, some clinicians with other caseloads described benefits, for example, increased patient services:

...provision of [additional] therapy sessions for rehab inpatients by students. (C18)

Across a range of caseloads, some clinicians also described making changes to ensure quality student and patient experiences. Several sought to accommodate student needs: for example, they 'try to see a variety of clients.' (C22). Additionally, a few clinicians linked meeting student needs to issues in maintaining quality and resulting impact on their stress:

Some increased stress due to delivering an equitable experience and still providing patients with adequate service. (C26) 


\section{Influence of student}

More than half the clinicians described the varied influence of student features on placement impact. For these clinicians, data suggest each placement experience depended on situational and personal student characteristics.

Some clinicians commented on the number of placement weeks when describing student impact. These clinicians perceived impacts more negatively in the early stages, and more positively as the placement progressed:

In the initial two-three weeks they do reduce the number of patients you can see in a day. Additionally in the final weeks of placement with the increasing capabilities of the students and their ability to take on more responsibility my clinical demand lightens. This frees me up to complete other non-clinical tasks or help out other members of the department with their clinical load. (C36)

Similarly, clinicians also described the student level as varying their work, suggesting more junior students required greater clinician time. Some clinicians perceived that less experienced students increased stress, while others only described differences such as reduced caseload management or administrative task completion:

For inpatients - for novice/intermediate students, a significantly increased time is needed for each [assessment/review], and therefore I feel I most often have capacity for less clinical load/occasions of service (which needs to be picked up by colleagues). - for more advanced students, then with planning this clinical capacity I think can be maintained, i.e. students can write notes, prep/follow up on [assessments] on their own so I can see other patients in this time. (C5)

Clinicians often identified challenges with students who required additional support. Clinician stress levels were always linked to student personal characteristics or whether they were at risk of failure. For example:

Increased stress levels when students are not competent (at their respective level of experience of course) or independent thinkers. A little bit of initiative goes a long way! (C15)

Some clinicians explained why at-risk students caused them stress: for example, having to seek assistance with caseload management. One clinician highlighted the burden of achieving a positive student outcome:

...because you feel it is your responsibility to get them across the line. (C35)

In contrast, students functioning at the expected level, or higher, were found not to cause the same stress and were described more positively: for example, '... an asset to our team.' (C23). These students were judged to have characteristics that required less supervisory time:

A high-achieving student who is strong at self reflection and is able to change skills with less teaching/feedback is much less (or virtually no) stress. (C28)

\section{Discussion}

This study sought to establish SP clinician perceptions of student impact on their work. Results showed clinicians perceive that students can positively or negatively impact clinical and non-clinical work tasks, time management and stress level. Clinicians perceived that students directly affected them professionally (e.g. patient activity levels) and personally (e.g. work hours), and impacted patients and colleagues. Increased stress during placements was commonly reported, although some clinicians perceived no increase in stress. Explaining these contrasting perspectives relates to the second study aim, which found multiple potential influences on the SP clinician experience of placements. Themes related to the individual clinician, to their supervision practices or workplace, and to student features. Indeed, just as the "decision to supervise a student is multi-factorial and often individual" (Hall et al., 2016, p. 147), data 
suggest that the nature of student impact is likely to be unique for each clinician and placement. These influences will be discussed with reference to existing literature.

\section{Influence of clinician}

It is perhaps not surprising that organisation and time-management skills emerged strongly as potential influences on clinician experience. These skills are important for SP clinicians generally (Lincoln et al., 2001), with students adding new responsibilities needing to be managed. While it seems logical that clinicians supervising multiple students mentioned this more often, further investigation should confirm whether this model requires greater skills or attention. Overall, findings are consistent with studies such as Evenson et al. (2015, p. 1) who found "workload or time" was the most dominant concern regarding occupational therapy placements. Further research could explore whether this area is pivotal in influencing student impact in SP, or whether, with more awareness of time available, clinicians can exert some control over it. Either way, some clinicians reported that time-management strategies (e.g. deferring non-clinical tasks) are not sustainable and clinicians are encouraged to refine their existing approaches to improve their placement experience.

In addition to implementing organisational strategies, this study suggests how clinicians cognitively and emotionally manage the various demands which may influence perceptions during placements. McAllister (2001) depicted the complexity as a clinician walking a tightrope between pillars of client needs versus student needs, whilst juggling considerations such as work duties or relationships with others. Furthermore, Attrill et al. (2016) suggested that high cognitive load may have negatively influenced judgements about time-use and other difficulties during placements with international SP students. While this needs further exploration, it is generally recognised that students "change the way workload is managed" (Davies et al., 2011, p. 228). Hence, techniques to ease any sense of burden, stress or negative impacts on time are needed. Clinician comments in this study suggest that flexibility in task management, an ability to maintain boundaries and a willingness to seek support are all positive approaches, but further research data is needed to analyse the use of specific strategies.

The benefits of student placements in enhancing clinician knowledge and reasoning skills shown in this study are consistent with SP (e.g. McCurtin \& Carter, 2015) and allied health studies (e.g. Evenson et al., 2015; O'Brien et al., 2017). However, this article contends that well-developed lifelong learning skills are the clinician characteristic that enables new perspectives from students to challenge existing knowledge and improve clinical practice. That is, clinicians who value students as an educational resource (Davies et

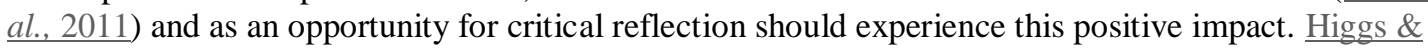
McAllister (2007, p. 194) highlight the importance of being a lifelong learner, positioning it in the underpinning dimension of a SP supervisor: "a sense of self". Since engagement in workplace learning can be challenging for allied health professionals (Lloyd et al., 2014), all efforts should be made to maximise these benefits for SP student supervisors and their workplace colleagues (e.g. through shared supervision).

\section{Influence of workplace}

Clinician comments on their placement experience often varied across service delivery model, clinical population and/or expected patient throughput. Allied health studies have identified similar factors that influence clinicians' decisions to supervise students (O'Brien et al., 2017; Varland et al., 2017).

Interestingly, neither positive nor negative impacts on clinical activity perceived in this study necessarily align with quantitative SP data (Bhagwat et al., 2018; Bourne, McAllister et al., 2019). Nevertheless, the existence of these beliefs poses a challenge in securing placements to help develop graduates with broadranging clinical competence. Furthermore, solutions to the challenges inherent in some settings are urgently required to ensure placements have a neutral or positive impact.

Importantly, this study has highlighted a potential mitigating influence on any negative aspects of SP student supervision - the availability of support from colleagues. Previous allied health studies have highlighted employer support as a contributory factor in participation in student placements (Davies et al., 2011; Maloney et al., 2013). Additionally it was apparent that, without workplace support, clinicians perceived supervising students as more stressful (Hall et al., 2016; Maloney et al., 2013). Broader team involvement was also identified as important in developing SP placements (Johnson et al., 2017) and to alleviate stress from a challenging physiotherapy student (Davies et al., 2011). Developing cultures that value student education should enhance placement management within SP workplaces. 


\section{Influence of supervision practices}

Selection of supervision approaches is challenging given the lack of evidence in SP. However, this study suggests clinicians who anticipate student needs, such as extra time, can implement a range of strategies, e.g. defining roles and responsibilities, and thereby experience positive or neutral impacts. The belief that students require extra time has been found in allied health studies (Sevenhuysen \& Haines, 2011), and SP studies have reported teaching time ranging from 50 to 111 minutes per day (Bourne, McAllister et al., 2019; Hancock, 1997). While quantitative data may not be based on efficient supervision models, the challenge for clinicians needing to accommodate student learning needs separately from patient activities is clear.

Supervising multiple students was linked to neutral or positive impacts by a few clinicians and may be the subject of additional research. Indeed, recent data showed taking two SP students had a neutral effect on clinical time and activity (Bhagwat et al., 2018). Furthermore, supervising two students was perceived as less stressful than with a single student in physiotherapy (Triggs Nemshick \& Shepard, 1996). Adult learning approaches that facilitate students to be self-directed may also benefit clinicians by reducing teaching time. Embedding effective supervision models within the workplace in partnership with universities should help counteract the known challenges in applying evidence in allied health clinical education (Delany \& Bialocerkowski, 2011). Additionally, bearing in mind that clinicians' supervision skills could be more important than the model itself (Dawes \& Lambert, 2010), linkage with universities should facilitate clinician skill development through mentoring and advanced training.

\section{Influence of student}

Variation in impact according to student level is consistent with perceptions in allied health professions (e.g. Hall et al., 2016). However, perceptions contrast with the limited quantitative differences in clinician time-use and activity levels found between early- and later-year placements, as reported by Bourne, McAllister et al. (2019). Further research could confirm whether clinicians either compensate for, or capitalise on, differing student abilities to maintain certain levels of patient care, for example, modifying caseload complexity or planning additional services. It is also possible that even small numerical differences have a large impact on clinicians, for example, adding role complexity. Certainly, as the student level is typically known before placement, planning strategies to minimise negative impacts or harness positive impacts should be prioritised. Additionally, the perception of student impact differing across the placement weeks is consistent with SP clinician time data (Bourne, McAllister et al., 2019). Hence, it would be prudent for clinicians to seek support and implement strategies to manage higher demands and reduce role strain, especially early in a placement.

Students with certain characteristics and/or difficulty developing expected skills were identified as having an impact, especially on clinician stress levels. Other allied health studies have highlighted similar concerns, for example, poor attitude (Hall et al., 2016). Clinician beliefs about students at risk of failure match quantitative data showing negative impacts on SP clinical time (Bourne et al., 2017). Clinician perceptions of increased stress with at-risk students are also consistent with allied health studies (e.g. Davies et al. 2011). To facilitate support strategies, future research should explore what aspects clinicians find most stressful, for example, whether it is related to patient risks reported by Morris (2001), or more psychosocial aspects such as stress from a greater sense of duty (Davies et al., 2011). Of further concern is that the fear of failing a student may influence placement offers (Varland et al., 2017) in allied health. Hence, it is vital for both clinician and student(s) that at-risk students are well-managed.

The implications of these preliminary findings are broad in scope. While validity and causality of identified factors have not been established, developing strategies to mitigate any negative influences seems justified given the commonalities with other disciplines. One way forward is to increase clinician awareness of potential factors affecting their experience, so that they can plan for, or adjust, those that are within their control. Reflective tools such as the Fieldwork Experience Assessment tool (Krupnick et al., 2002) could be adapted to guide clinician self-evaluation prior to placement, to promote a positive placement experience. In addition, and comparable to other areas of clinical practice, clinicians should participate in training, mentoring and support programs to ensure that they reflect on and refine their supervision skills over time. 


\section{Limitations}

While this research shows consistency with qualitative data in SP and other allied health professions, it is situated within one public health sector setting and results may not reflect experiences in other contexts. Furthermore, as participants self-selected as part of a larger study, the sample may be biased as it excluded managers and others who had chosen not to supervise students. Hence, reported perceptions could be skewed towards those who consider the advantages of student supervision outweigh any negative aspects. In addition, data-gathering using open-ended survey questions did not enable prompting for positive and negative perceptions of student impact in each topic. It also did not probe for or highlight other potential factors (e.g. international students in Attrill et al., 2016). Thus, it is unlikely data saturation has been achieved. Future research using qualitative approaches such as focus groups or individual interviews is recommended for more in-depth exploration of what has proved a highly complex situation.

\section{Conclusion}

This study is a step forward in understanding the perceptions of SP clinicians offering student placements and confirms that their experience is similar to other allied health professions. For the first time, a model has been developed highlighting the interface of four factors that may influence SP clinician perceptions of student impact: the individual clinician; their supervision practices; the workplace; and the student(s). Further research should ascertain the significance of specific factors and what combination of factors is crucial to positive or negative experiences during placements.

\section{Acknowledgements}

The authors wish to acknowledge the contribution of Dr Srivalli Nagarajan (SN) to project design and early data coding

\section{Ethical approval}

University of Sydney Human Research Ethics Committee (HREC) Project No. 2014/914.

Approval also granted separately from HREC committees in six health districts in one state of Australia.

\section{ORCID}

Elizabeth Bourne
Lindy McAllister
Belinda Kenny
Kate Short $\quad \begin{aligned} & \text { http://orcid.org/0000-0003-2501-193X } \\ & \text { http://orcid.org/0000-0001-8715-3971 } \\ & \text { http://orcid.org/0000-0002-5054-7309 }\end{aligned}$

\section{References}

Attrill, S., Lincoln, M., \& McAllister, S. (2016). Supervising international students in clinical placements: Perceptions of experiences and factors influencing competency development. BMC Medical Education, 16. Article 180. https://doi.org/10.1186/s12909-016-0702-5

Barton, R., Corban, A., Herrli-Warner, L., McClain, E., Riehle, D., \& Tinner, E. (2013). Role strain in occupational therapy fieldwork educators. Work, 44(3), 317-328. https://doi.org/10.3233/WOR$\underline{121508}$

Bhagwat, M., Hewetson, R., Jones, L., Hill, A., Nunn, J., Tosh, R., \& Cahill, L. (2018). Comparison of paired and single clinical placement models: a time-use analysis. International Journal of Language \& Communication Disorders, 53(3), 468-479. https://doi.org/10.1111/14606984.12360

Bourne, E., McAllister, L., Nagarajan, S., \& Short, K. (2017, May 28-31). The effect of student competence on speech pathology clinician time use and productivity. A quantitative study in NSW Health. [Paper presentation]. Speech Pathology Australia 2017 National Conference, Sydney, Australia. 
Bourne, E., McAllister, L., Nagarajan, S., \& Short, K. (2019). The effect of speech-language pathology students on clinician time use and activity. International Journal of Speech-Language Pathology, 21(2), 163-174. https://doi.org/10.1080/17549507.2017.1416175

Bourne, E., Short, K., McAllister, L., \& Nagarajan, S. (2019). The quantitative impact of placements on allied health time use and productivity in healthcare facilities: A systematic review with metaanalysis. Focus on Health Professional Education, 20(2), 8-40. https://doi.org/10.11157/fohpe.v20i2.315

Briffa, C., \& Porter, J. (2013). A systematic review of the collaborative clinical education model to inform speech-language pathology practice. International Journal of Speech-Language Pathology, 15(6), 564-574. https://doi.org/10.3109/17549507.2013.763290

Cocks, N., Harding, C., \& Pritchard, M. (2014). The benefits of a 5-day dysphagia intensive placement. International Journal of Speech-Language Pathology, 16(5), 476-485. https://doi.org/10.3109/17549507.2013.826283

Davies, R., Hanna, E., \& Cott, C. (2011). 'They put you on your toes': Physical therapists' perceived benefits from and barriers to supervising students in the clinical setting. Physiotherapy Canada, 63(2), 224-233. https://doi.org/10.3138/ptc.2010-07

Dawes, J. M., \& Lambert, P. B. (2010). Practice educators' experiences of supervising two students on allied health practice-based placements. Journal of Allied Health, 39(1), 20-27. https://www.ingentaconnect.com/content/asahp/jah/2010/00000039/00000001/art00006

Delany, C., \& Bialocerkowski, A. (2011). Incorporating evidence in clinical education; barriers and opportunities in allied health. The Internet Journal of Allied Health Sciences and Practice, 9(1), $1-16$.

Evenson, M. E., Roberts, M., Kaldenberg, J., Barnes, M. A., \& Ozelie, R. (2015). National Survey of Fieldwork Educators: Implications for occupational therapy education. American Journal of Occupational Therapy, 69(Supplement_2), 1-5. https://doi.org/10.5014/ajot.2015.019265

Foo, J., Rivers, G., Ilic, D., Evans, D. J. R., Walsh, K., Haines, T., Paynter, S., Morgan, P., Lincke, K., Lambrou, H., Nethercote, A., \& Maloney, S. (2017). The economic cost of failure in clinical education: A multi-perspective analysis. Medical Education, 51(7), 740-754. https://doi.org/10.1111/medu.13266

Francis, A., Hills, C., MacDonald-Wicks, L., Johnston, C., James, D., Surjan, Y., \& Warren-Forward, H. (2016). Characteristics of an ideal practice educator: Perspectives from practice educators in diagnostic radiography, nuclear medicine, nutrition and dietetics, occupational therapy and physiotherapy and radiation therapy. Radiography, 22(4), 287-294. https://doi.org/10.1016/j.radi.2016.04.001

Hall, M., Poth, C., Manns, P., \& Beaupre, L. (2016). An exploration of Canadian physiotherapists' decisions about whether to supervise physiotherapy students: Results from a national survey. Physiotherapy Canada, 68(2), 141-148. https://doi.org/10.3138/ptc.2014-88E

Hancock, J. J. (1997). Impact of Speech-Language Pathology Students on Patient Care [Unpublished master's thesis]. University of Alberta. https://era.library.ualberta.ca/items/7ee450ba-4c6b-4e1f99c4-95a6df862e3a

Harris, P. A., Taylor, R., Thielke, R., Payne, J., Gonzalez, N., \& Conde, J. G. (2009). Research electronic data capture (REDCap) - A metadata-driven methodology and workflow process for providing translational research informatics support. Journal of Biomedical Informatics, 42(2), 377-381. https://doi.org/10.1016/j.jbi.2008.08.010

Higgs, J., \& McAllister, L. (2007). Being a clinical educator. Advances in Health Sciences Education, 12, 187-200. https://doi.org/10.1007/s10459-005-5491-2

Hsieh, H.-F., \& Shannon, S. E. (2005). Three approaches to qualitative content analysis. Qualitative Health Research, 15(9), 1277-1288. https://doi.org/10.1177/1049732305276687

Hunt, M. R. (2009). Strengths and challenges in the use of interpretive description: Reflections arising from a study of the moral experience of health professionals in humanitarian work. Qualitative Health Research, 19(9), 1284-1292. https://doi.org/10.1177/1049732309344612

Ingwersen, K., Lyons, N., \& Hitch, D. (2017). Perceptions of fieldwork in occupational therapy. The Clinical Teacher, 14(1), 55-59. https://doi.org/10.1111/tct.12518

Johnson, R., Bourne, E., Sheepway, L., \& McAllister, L. (2017). Expanding volume and quality of clinical placements: The Capacity Development Facilitation framework in speech-language pathology. Journal of Clinical Practice in Speech Language Pathology, 19(2), 93-99.

Krupnick, W., Brown, K., \& Stutz-Tanenbaum, P. (2002). Creating a successful fieldwork experience: The fieldwork experience assessment tool. OT Practice, 7(2), CE 1-8. 
Lincoln, M. A., Adamson, B. J., \& Cant, R. V. (2001). The importance of managerial competencies for new graduates in speech pathology. Advances in Speech Language Pathology, 3(1), 25-36. https://doi.org/10.3109/14417040109003706

Lincoln, Y., \& Guba, E. (1985). Naturalistic inquiry. Sage.

Lloyd, B., Pfeiffer, D., Dominish, J., Heading, G., Schmidt, D., \& McCluskey, A. (2014). The New South Wales Allied Health Workplace Learning Study: Barriers and enablers to learning in the workplace. BMC Health Services Research, 14, Article 134. https://doi.org/10.1186/1472-696314-134

Maloney, P., Stagnitti, K., \& Schoo, A. (2013). Barriers and enablers to clinical fieldwork education in rural public and private allied health practice. Higher Education Research \& Development, 32(3), 420-435. https://doi.org/10.1080/07294360.2012.682255

Mancinelli, J. M., \& Amster, B. J. (2015). Rethinking clinical education: To keep pace with the demand for SLPs, graduate programs need to increase their capacity. But for that to happen, the rules for clinical education must change. The ASHA Leader, 20(1), 6-7. https://doi.org/10.1044/leader.FMP.20012015.6

McAllister, L. (2001). The experience of being a clinical educator [Unpublished doctoral dissertation]. The University of Sydney. https://ses.library.usyd.edu.au/bitstream/handle/2123/4017/The\%20Experience\%20of\%20Being $\% 20 \mathrm{a} \% 20 \mathrm{Clinical} \% 20$ Educator.pdf? sequence $=1$

McCurtin, A., \& Carter, B. (2015). 'We don't have recipes; we just have loads of ingredients': Explanations of evidence and clinical decision making by speech and language therapists. Journal of Evaluation in Clinical Practice, 21(6), 1142-1150. https://doi.org/10.1111/jep.12285

Morris, C. (2001). Student supervision: Risky business? International Journal of Language \& Communication Disorders, 36(Supplement 1), 156-161. https://doi.org/10.3109/13682820109177876

O’Brien, C. W., Anderson, R., Ayzenberg, B., Chute, P., Farnsworth, T., McLaughlin, R., Romig, B., Samonian, Y., Sample, J., Tynsky, T., Wallace, B., Weinstein, M., \& O'Sullivan Maillet, J. (2017). Employers' viewpoint on clinical education. Journal of Allied Health, 46(3), 131-137. https://www.ingentaconnect.com/content/asahp/jah/2017/00000046/00000003/art00004

Öhman, A., Hägg, K., \& Dahlgren, L. (2005). A stimulating, practice-based job facing increased stress Clinical supervisors' perceptions of professional role, physiotherapy education and the status of the profession. Advances in Physiotherapy, 7(3), 114-122. https://doi.org/10.1080/14038190510010359

Read, J. (2014). The future of clinical education in speech and language therapy. International Journal of Therapy and Rehabilitation, 21(11), 506-507. https://doi.org/10.12968/ijtr.2014.21.11.506

Ryan, C., \& McAllister, M. (2018). The experiences of clinical facilitators working with nursing students in Australia: An interpretive description. Collegian, 26(2), 281-287. https://doi.org/10.1016/j.colegn.2018.07.005

Sevenhuysen, S. L., \& Haines, T. (2011). The slave of duty: Why clinical educators across the continuum of care provide clinical education in physiotherapy. Hong Kong Physiotherapy Journal, 29(2), 64-70. https://doi.org/10.1016/j.hkpj.2011.06.002

Thomasz, T., \& Young, D. (2016). Speech pathology and occupational therapy students participating in placements where their supervisor works in a dual role. Australian Journal of Rural Health, 24(1), 36-40. https://doi.org/10.1111/ajr.12238

Thorne, S. E. (2016). Interpretive description: Qualitative research for applied practice (2nd ed.) Routledge. https://doi.org/10.4324/9781315545196

Thorne, S., Kirkham, S. R., \& O'Flynn-Magee, K. (2004). The analytic challenge in interpretive description. International Journal of Qualitative Methods, 3(1), 1-11. https://doi.org/10.1177/160940690400300101

Triggs Nemshick, M., \& Shepard, K. F. (1996). Physical therapy clinical education in a 2:1 studentinstructor education model. Physical Therapy, 76(9), 968-981. https://doi.org/10.1093/ptj/76.9.968

Varland, J., Cardell, E., Koski, J., \& McFadden, M. (2017). Factors influencing occupational therapists' decision to supervise fieldwork students. Occupational Therapy in Health Care, 31(3), 238-254. https://doi.org/10.1080/07380577.2017.1328631 
Appendix: Initial categories and codes with example quotes

\begin{tabular}{|c|c|c|c|c|}
\hline Question & Category & Code & Example quotes & $\begin{array}{l}\text { Participant } \\
\text { number }\end{array}$ \\
\hline \multirow{10}{*}{$\begin{array}{l}\text { What } \\
\text { effect do } \\
\text { you } \\
\text { believe } \\
\text { students } \\
\text { have on } \\
\text { your } \\
\text { clinical } \\
\text { work? }\end{array}$} & \multirow{4}{*}{$\begin{array}{l}\text { Impact on } \\
\text { Patient } \\
\text { Activity }\end{array}$} & Increase & $\begin{array}{l}\text { They increase the number of clients that are seen as } \\
\text { trying to provide them with a range of learning } \\
\text { experiences. Waiting lists decrease }\end{array}$ & C3 \\
\hline & & Decrease & $\begin{array}{l}\text { I can't generally book as many clients, or complete and } \\
\text { many tasks per session as I would typically. }\end{array}$ & $\mathrm{C} 22$ \\
\hline & & Maintenance & I would see similar numbers $+/$ - students & $\mathrm{C} 13$ \\
\hline & & Student Variation & $\begin{array}{l}\text { Alter pts seen - try to find them extra experiences } \\
\text { outside of my daily role }\end{array}$ & $\mathrm{C} 21$ \\
\hline & \multirow[b]{3}{*}{$\begin{array}{l}\text { Impact on } \\
\text { Time }\end{array}$} & Clinical time & Diminish speed at which I can see patients & $\mathrm{C} 24$ \\
\hline & & Students take time & $\begin{array}{l}\text { Increased time to see patients e.g. talking through } \\
\text { sessions, checking notes, debriefing etc. etc. }\end{array}$ & $\mathrm{C} 14$ \\
\hline & & $\begin{array}{l}\text { Caseload } \\
\text { dependent }\end{array}$ & $\begin{array}{l}\text { The clinical speciality requires a high level of } \\
\text { supervision, and depends on the caseload at the time if } \\
\text { the clinician can be left independently with [patient] to } \\
\text { cont. their programme. }\end{array}$ & $\mathrm{C} 30$ \\
\hline & \multirow{3}{*}{$\begin{array}{l}\text { Impact on } \\
\text { Clinician }\end{array}$} & $\begin{array}{l}\text { Improves } \\
\text { organisation and } \\
\text { time management }\end{array}$ & $\begin{array}{l}\text { Provides a focus to be more organised with admin tasks, } \\
\text { especially tasks I have to teach / handover to students }\end{array}$ & $\mathrm{C} 2$ \\
\hline & & Promotes EBP & $\begin{array}{l}\text { Improves my ability to explain clinical concepts, keeps } \\
\text { me up to date with the latest evidence }\end{array}$ & $\mathrm{C} 31$ \\
\hline & & $\begin{array}{l}\text { Teaching } \\
\text { practices }\end{array}$ & $\begin{array}{l}\text { I also enjoy the responsibility of providing a supportive } \\
\text { environment for the students to grow and develop } \\
\text { clinical and non-clinical skills as clinicians. }\end{array}$ & C9 \\
\hline \multirow{7}{*}{$\begin{array}{l}\text { What } \\
\text { effect do } \\
\text { you } \\
\text { believe } \\
\text { students } \\
\text { have on } \\
\text { your other } \\
\text { work } \\
\text { tasks? }\end{array}$} & & Students take time & Less time to 'focus' on other tasks during student blocks. & $\mathrm{C} 24$ \\
\hline & $\begin{array}{l}\text { Impact of } \\
\text { Student }\end{array}$ & $\begin{array}{l}\text { Depends on } \\
\text { student }\end{array}$ & $\begin{array}{l}\text { Depends on the students - it sometimes allows } \\
\text { additional time for [quality improvement] project, admin } \\
\text { tasks etc.; sometimes I find a lot of time is spent } \\
\text { supervising and I end up doing my own work after } \\
\text { hours. }\end{array}$ & $\mathrm{C} 2$ \\
\hline & \multirow{3}{*}{$\begin{array}{l}\text { Responses } \\
\text { to Impact }\end{array}$} & Tasks delayed & $\begin{array}{l}\text { Ability to complete QI projects and admin tasks during } \\
\text { work hours decreases. I usually find I need to do some } \\
\text { of this after hours. }\end{array}$ & $\mathrm{C} 8$ \\
\hline & & $\begin{array}{l}\text { Systems to } \\
\text { manage }\end{array}$ & $\begin{array}{l}\text { It will be important to be able to find general tasks for } \\
\text { the students to complete during the day so that I can } \\
\text { keep on top of my other work - as it is unrealistic for me } \\
\text { to not complete any of this work across a six week } \\
\text { placement. }\end{array}$ & C16 \\
\hline & & Change priorities & $\begin{array}{l}\text { Often have to deprioritise non clinical work to be with } \\
\text { the students and providing them with the clinical } \\
\text { support they need }\end{array}$ & $\mathrm{C} 17$ \\
\hline & \multirow{2}{*}{$\begin{array}{l}\text { Impact on } \\
\text { Clinician }\end{array}$} & $\begin{array}{l}\text { Sense of stress or } \\
\text { pressure }\end{array}$ & $\begin{array}{l}\text { Unfortunately, students have a negative impact on my } \\
\text { ability to complete other work tasks, and this results in } \\
\text { stress }\end{array}$ & $\mathrm{C} 33$ \\
\hline & & $\begin{array}{l}\text { Physical space } \\
\text { limitations }\end{array}$ & $\begin{array}{l}\text { There is also no other space for students to be in, they } \\
\text { are in my office whether we are seeing a client or I am } \\
\text { doing other tasks, which can feel a bit odd. }\end{array}$ & $\mathrm{C} 22$ \\
\hline \multirow{6}{*}{$\begin{array}{l}\text { What } \\
\text { effect do } \\
\text { you } \\
\text { believe } \\
\text { students } \\
\text { have on } \\
\text { your time } \\
\text { manage- } \\
\text { ment? }\end{array}$} & \multirow{2}{*}{$\begin{array}{l}\text { Positive } \\
\text { impact }\end{array}$} & $\begin{array}{l}\text { Better time } \\
\text { management and } \\
\text { organisation }\end{array}$ & $\begin{array}{l}\text { They improve my time management as I have to plan } \\
\text { out the day and work out how best to fit in all the tasks. } \\
\text { they help me prioritise work. }\end{array}$ & $\mathrm{C} 3$ \\
\hline & & $\begin{array}{l}\text { Provides } \\
\text { assistance with } \\
\text { some tasks }\end{array}$ & Assists with completing some tasks & $\mathrm{C} 12$ \\
\hline & \multirow[t]{2}{*}{$\begin{array}{l}\text { Neutral/ } \\
\text { limited } \\
\text { impact }\end{array}$} & Manageable & $\begin{array}{l}\text { When students are progressing well through their } \\
\text { placement time management may only be minimally } \\
\text { impacted upon }\end{array}$ & $\mathrm{C} 29$ \\
\hline & & Little/ no effect & Not too much of an effect. & $\mathrm{C} 1$ \\
\hline & \multirow{2}{*}{$\begin{array}{l}\text { Negative } \\
\text { impact }\end{array}$} & $\begin{array}{l}\text { Increases work } \\
\text { hours }\end{array}$ & Usually leave a little late & C37 \\
\hline & & $\begin{array}{l}\text { Affects clinical } \\
\text { and }\end{array}$ & $\begin{array}{l}\text { Fitting in student supervision appears to add more } \\
\text { clinical and admin tasks }\end{array}$ & $\mathrm{C} 15$ \\
\hline
\end{tabular}




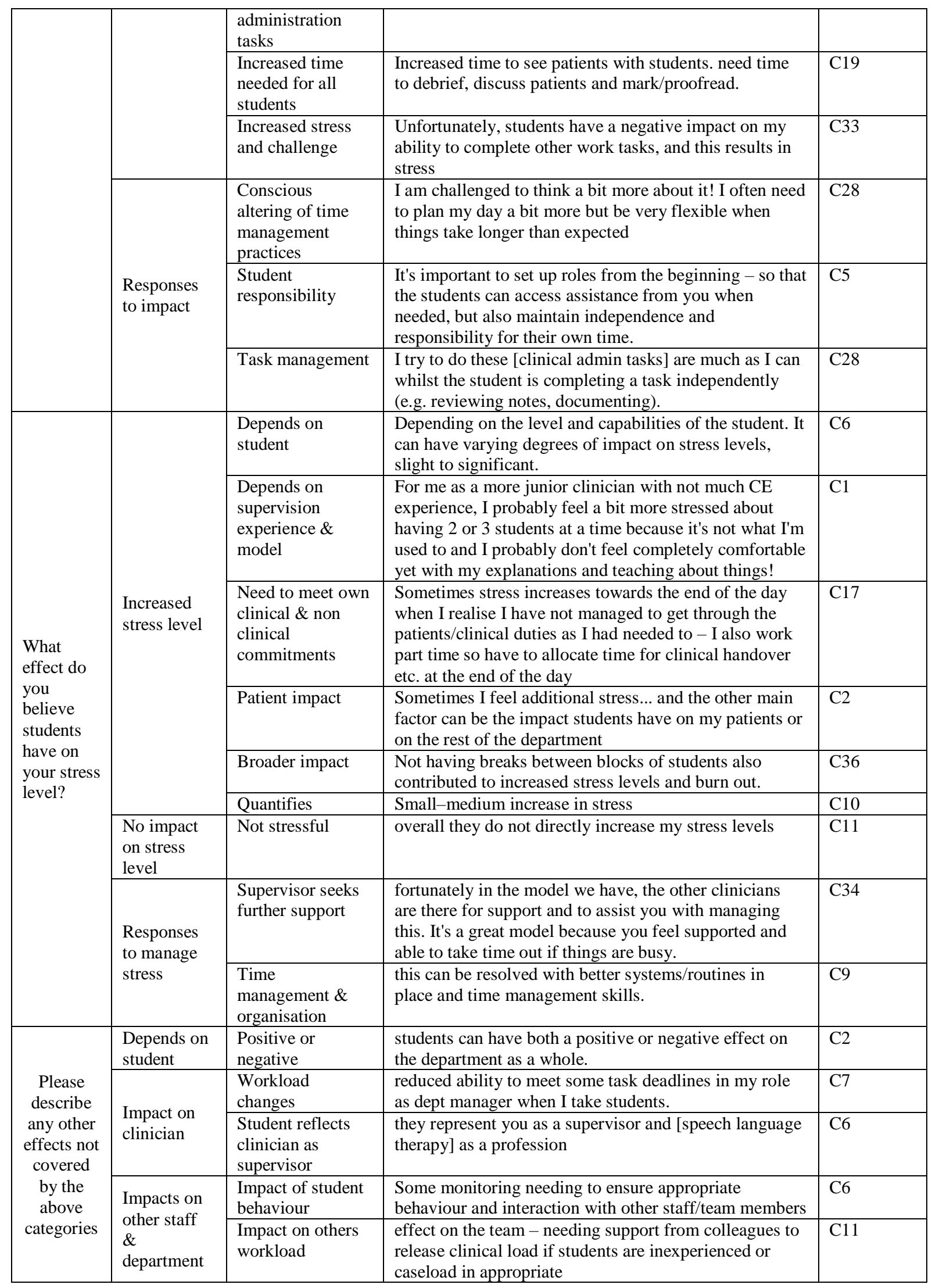

